\title{
Basal cell carcinoma of the skin with clear cell differentation: A report of two cases
}

\author{
Vladimír Bartoš¹, Tatiana Bulejčíková2 \\ ${ }^{1}$ Department of Pathology, Faculty Hospital in Žilina, V. Spanyola 43, Žilina, 012 07, Slovakia, ${ }^{2}$ Department of \\ Dermatovenerology, Faculty Hospital in Žilina, V. Spanyola 43, Žilina, 012 07, Slovakia
}

Corresponding author: Vladimír Bartoš, MD, PhD, MSc., E-mail: vladim.bartos@gmail.com

\begin{abstract}
Basal cell carcinoma with clear cell differentiation is extremely rare variant of this cutaneous malignancy. Here, two new cases are described in a 68-year old man arising on the scapula and in a 76-year old man arising on the face. Histologically, sharply demarcated islands consisting of the large cells with clear and focally foamy cytoplasm were found within a conventional nodular and superficial-nodular basal cell carcinoma. In both cases, clear cell population showed no mitoses, low or absent proliferative activity and was immunohistochemically positive for p 53 protein. In one case, it apparently stained with alcian blue, but not with periodic acid-Shiff method, suggesting the accumulation of acid mucopolysacharides. Present results are compared with the literature data and knowledge on histogenesis of this tumor entity is discussed.
\end{abstract}

Key words: Basal cell carcinoma; Clear cell differentiation; Histological subtypes

\section{INTRODUCTION}

Basal cell carcinoma (BCC) of the skin exhibits a very heterogeneous histomorphology. This neoplasia is thought to arise from pluripotent stem cells in the epidermis that are capable of differentiating into pilosebaceous unit or sweat glands [1]. Perhaps as a consequence, there is marked histopathologic diversity among BCC, and many subtypes and variants have been described until now [1-4]. When classifying BCCs, most authors start from the growth pattern, which gives more information about biological behavior [2]. Based on it, nodular, superficial and infiltrative (morpheic) BCCs are the most common subtypes representing the vast majority of diagnosed cases [2,3]. In addition to these conventional (sometimes referred to as undifferentiated) subtypes, several unusual (differentiated) BCC variants showing a variety of specific cell lineage differentiation features have also been described $[1,3,4]$. However, the only proven histologic prognosticator of biologic behaviour, and therefore a key determinant of what constitutes an appropriate therapeutic strategy, is the architectural growth pattern. Thus, the microarchitecture is an essential issue, while the differentiation features need to be considered only insofar as they impact differential diagnosis [3]. A spectrum of various differentiated and unusual variants of BCC are precisely reported and illustrated in the textbook published by Kazakov et al. [4]. Amongst these, the clear cell variant is very rare entity. Histologically, it manifests apparent clear cell change in tumor tissue, the extent of which ranges from focal to striking $[1,4]$. Nowadays, data about its origin and pathogenesis are sparse and controversial in many aspects. Moreover, it is not definitive elucidated, whether it represents a form of true specific histogenetic differentiation, or only a degenerative phenomenon. Herein, we briefly present two patients, who were diagnosed to have this peculiar dermatopathological entity. We also tried to explain its percentage proportion in the large cohort of consecutively diagnosed cutaneous BCCs. 


\section{CASE PRESENTATION}

\section{Case 1}

A 76-year old male manifested with a dome-shaped ulcerated tumor on the right side of the face above zygomatic arch. On physical examination, the lesion was well-defined, light brown and 9x9 $\mathrm{mm}$ in size. A presumptive clinical diagnosis of $\mathrm{BCC}$ was made. A total surgical extirpation was carried out at the outpatients' dermatology department and a biopsy sample was send for histopathological examination. Hematoxylin and eosin (H\&E) stained paraffin sections revealed a conventional nodular BCC containing large, sharply demarcated islands consisting of the large cells with clear and focally foamy cytoplasm (Fig. 1). Ocassionally, condensed nuclei were pushed to the edge giving a signet-ring appearence. In certain areas, peculiar zonation with peripheral palisading of the clear cells with their nuclei located at the opposite pole from the basement membrane have been discerned (Fig. 2). This clear cell population stained apparently with alcian blue at pH 2.3 (Fig. 3), but not with periodic acid-Shiff (PAS) method (Fig. 4), suggesting the accumulation of acid mucopolysacharides. Immunohistochemical examination revealed a similar diffuse staining with protein p53 (clone DO-7, DAKO, dilution 1: 50) in both, basaloid and clear cell components (Fig. 5). The expression of proliferative Ki-67 antigen (clone MM1, LEICA, dilution 1: 200) was low $(<10 \%)$ in the basaloid cancer nests and virtually absent in the clear cell population. No mitotic figures were found in both tumor components. Based on histopathology, a diagnosis of nodular $\mathrm{BCC}$ with clear cell differentiation was made. Resection margins were free of tumor and no local recurrence has been observed.

\section{Case 2}

A 68-year-old male presented with slightly protuberant cutaneous tumor on his left scapular region. The lesion was gray-brownish and measured $25 \times 15 \mathrm{~mm}$. The clinical impression was BCC. At the outpatients' department od dermatology, the tumor was partially excised (probatory biopsy) and a sample was send for histological investigation. The pathologic examination showed mixed superficial-nodular BCC that manifested all features of ordinary BCC. However, a sharply defined nests composed of the clear cells were observed within a typical basaloid tumor component (Fig. 6). The cells had striking appearance with a large

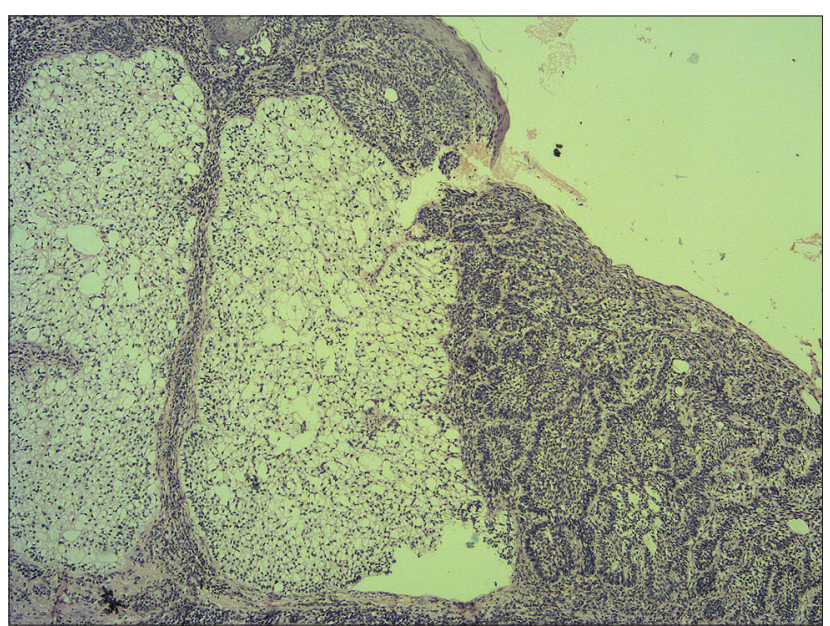

Figure 1: Case 1. A sharp demarcation between a conspicous clear cell population (left) and a conventional basaloid tumor tissue (right). (H\&E, original magnification 120x).

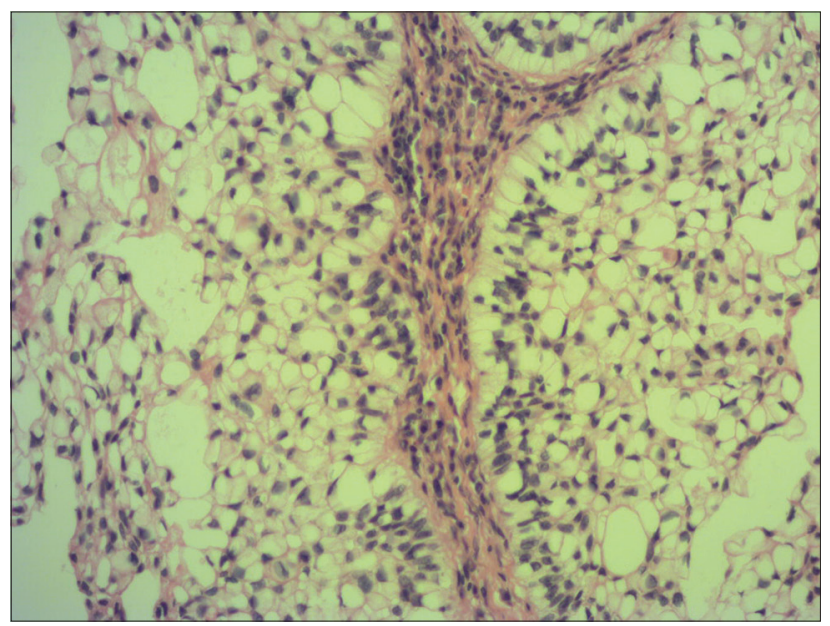

Figure 2: Case 1. Detail on peripheral palisading of the clear cells with their nuclei located at the opposite pole from the basement membrane. This feature is reminiscent of trichilemmal differentiation. (H\&E, original magnification 240x).

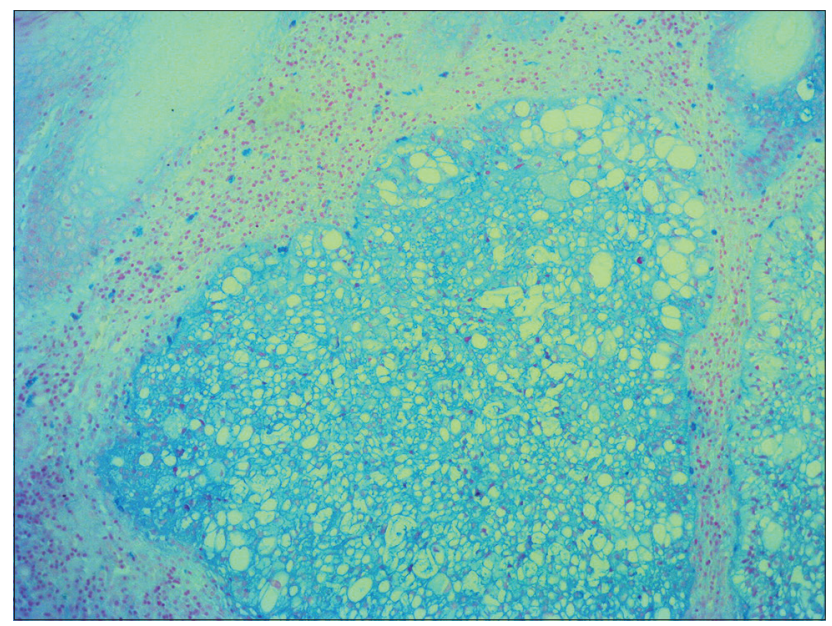

Figure 3: Case 1. Diffuse and intensive staining of the clear cell population with alcian blue. (original magnification 120x). 


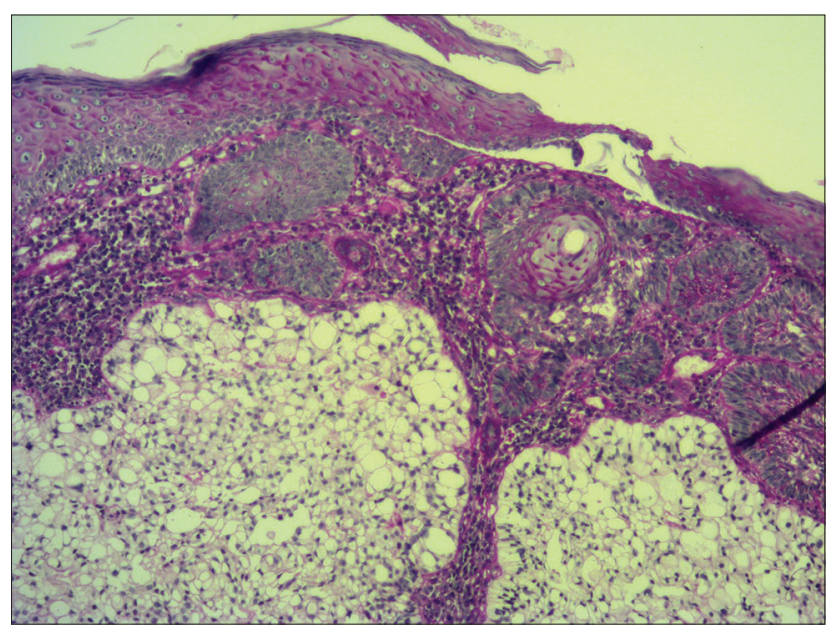

Figure 4: Case 1. Negative staining of the clear cell population with periodic acid-Shiff (PAS) method. (original magnification 120x).

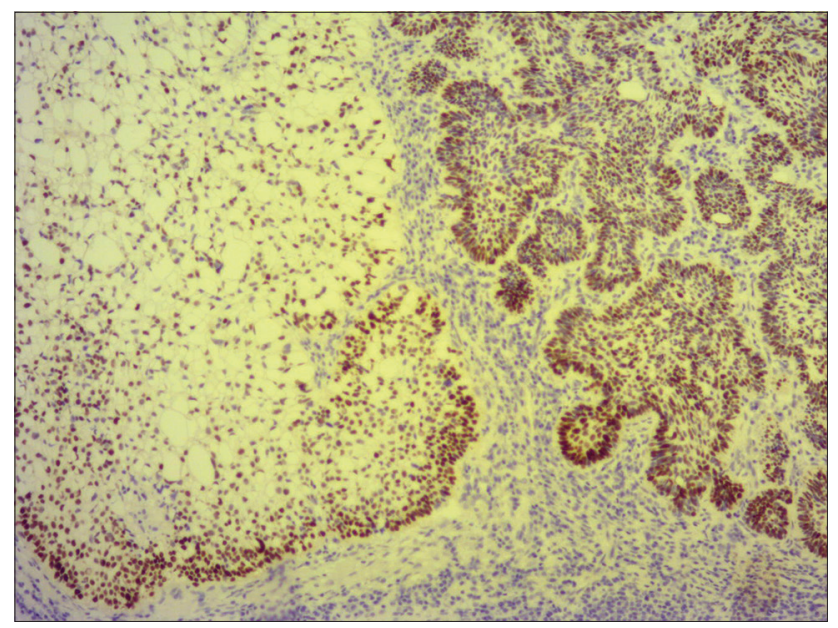

Figure 5: Case 1. Immunohistochemical reactivity for protein p53 with nearly the same extent in both, basaloid (right) and clear cell (left) tumor components. (antibody against p53, clone DO-7, original magnification 240x).

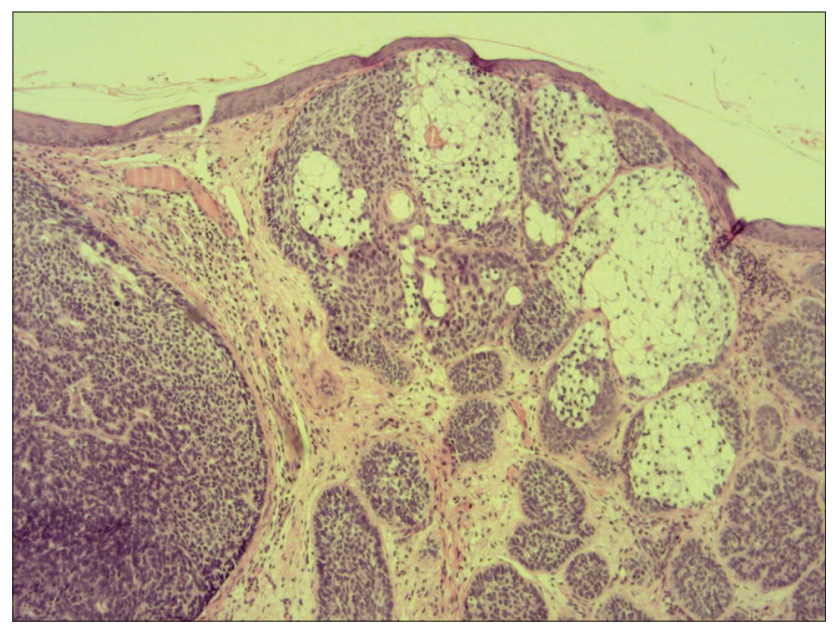

Figure 6: Case 2. Islands of the clear cells (right) within a typical basaloid tumor component (H\&E, original magnification 120x). clear cytoplasm and a small, dark nuclei. They also showed a tendency of faint palisading at the periphery in some histologic sections. No mitotic figures were seen in the clear cell component in contrast to basaloid tumor part. Immunohistochemical study showed positive staining for protein p53 (clone DO-7, DAKO, dilution 1: 50) with nearly the same extent in both components. Expression of Ki-67 antigen (clone MM1, Leica, dilution 1:200) was less pronounced in the clear cell population $(<10 \%)$ compared to conventional nodular tumor islands (20\%). Unfortunatelly, other special histopathological investigations would have been worthless, because clear cell component had dissapeared during processing of the tissue specimen. A pathologic diagnosis of superficial-nodular BCC with clear cell differentiation was established. The lesion was further treated by local application of Efudix cream.

\section{DISCUSSION}

Clear cell BCC is exceedingly rare histologic variant of this common cutaneous neoplasm. In 1984, Barr \& Williamson [5] were probably the first, who reported it in the medical journal and since that time, there have been approximatelly 30 cases published in the English-language literature [6]. In our current paper, we present an additional two cases. As a result of very sporadic reporting, reliable data concerning the occurrence, histogenesis and clinicopathological aspects of this BCC variant are insufficient. Therefore, we attempted to estimate its prevalence and for this purpose, we analysed all consecutive BCCs of the skin registered in the database of our Department of Pathology between January 2007 and May 2016. During this nearly 10 -year period, a total of 1115 primary cutaneous BCCs were diagnosed, of which only these two ones $(0.17 \%)$ exhibited such unique microscopic feature.

In the clear cell BCC variant, the clear cell pattern may occupy all or a part of the tumor islands $[1,4]$. In both present cases, it comprised a minor proportion of a given cancer tissue. Our findings are consistent with those of a previous studies that reported [6-9], nodular BCC subtype has been seen in association with this phenomenon in the vast majority of the cases. Since the clear cell changes in cutaneous BCC often affect a tumor tissue only partially and probably do not have prognostic significance, someone can debate, as to 
whether it would not be better to use a term „clear cell“ only as additional description, for example superficial or nodular BCC with clear cell differentiation (pattern). In our patients, such terminology was preferred. A designation clear cell BCC per se does not provide an information on growth pattern, that is much more important for the clinicians.

The clear cell population in BCC usually contains intracytoplasmic glycogen vacuoles, that often cause peripheral displacement of the nucleus, giving them a signet ring appearence in some cases [1]. However, histochemical observations between cases have been inconsistent. While periodic acid-Shiff (PAS) staining with or without diastase has been positive for glycogen in some cases $[5,7,10,11]$, other authors revealed only sparse or no PAS positivity $[6,8,9,12,13]$, such as in the current case. In addition, Kim et al. [10] noted the presence of sialomucin deposition and they hypothesized, sialomucin in clear cell BCC might be obtained as one of the products of tumor glandular differentiation. Even in the current study, Case 1 showed intracellular acummulation of acid mucopolysacharides, a finding that may support this idea. Electron microscopic studies have also been variable, as some have found the large intracellular vacuoles to be membrane bound $[13,14]$, while the others have not $[7,9,12]$. Therefore, it is not suprising, an origin of the clear cell population in BCC is not fully understood. Barr \& Williamson [5] initially suggested, its pathogenesis was related to trichilemmal differentiation. However, many investigators subsequently considered the large vacuoles, which occupied the cytoplasm on electron microscopy, as phagolysomes or end-stage products of intracellular organelles $[7,13,14]$. Thus, clear cell changes were later thought to be a degenerative phenomenon. Nevertheless, an alternative view is inclined to believe that this finding recapitulates outer root sheath (trichilemmal) differentiation due to characteristic palisading of peripherally located clear cells $[3,4]$. This feature was visible in both our cases, too. Furthermore, because the clear cell islands were coherent and sharply demarcated from the surrounding cancer tissue, that did not show any regressive changes, we are more likely to think, it is not a degenerative phenomenon but a form of a special histogenetic differentiation. Since both, conventional basaloid and clear cell population shared a similar pattern of p 53 expression, molecular alterations of p 53 gene probably play a central role in the development of both tumor parts.

In conclusion, despite the rarity in a routine dermatopathological practice, due to potential diagnostic difficulties, the pathologist should be aware of this unusual BCC variant. Especially in a limited biopsy specimen containing little or no conventional areas of $\mathrm{BCC}$, distinguishing the tumor from another skin neoplasms with clear cell pattern (e.g., sebaceous carcinoma, hidroadenocarcinoma or metastatic renal cell carcinoma) may be difficult. In such cases, a possible diagnosis of $\mathrm{BCC}$ with clear cell differentiation should be kept in mind.

\section{Consent}

The examination of the patients was conducted according to the Declaration of Helsinki principles.

\section{ACKNOWLEDGMENTS}

The authors would like to thank Dr. Pokorný Dušan, Dr. Jančovičová Viktória and Ms. Hanajíková Tat'ána for their outstanding educational and technical assistance.

\section{REFERENCES}

1. Elder DE, Elenitsas R, Johnson BL jr, Xu G. Lever's Histopathology of the Skin. Tenth Edition. Wolters Kluwer Health/Lippincott Williams \& Wilkins, Philadelphia. 2009. 1408 pages. ISBN 978-0781773638

2. Vantuchová Y, Črúḱ R. Histological types of basal cell carcinoma. Scripta Medica (Brno) 2006; 79: 261-270.

3. Crowson AN. Basal cell carcinoma: biology, morphology and clinical implications. Mod Pathol 2006; 19: S127-S147.

4. Kazakov DV, Michal M, Kacerovska D, McKee PH. Cutaneous Adnexal Tumors. Wolters Kluwer Health/Lippincott Williams \& Wilkins, Philadelphia, 2012. 814 pages. ISBN 978-1605478548

5. Barr RJ, Williamson C. Clear-cell basal cell carcinoma. Arch Dermatol 1984; 120:1086.

6. Sarma DP, Olson D, Olivella J et al. Clear cell basal cell carcinoma. Pathol Res Int 2011; 2011:386921.

7. Barnadas MA, Freeman RG. Clear cell basal cell epithelioma: light and electron microscopic study of an unusual variant. J Cutan Pathol 1988; 15: 1-7.

8. Forman SB, Ferringer TC. Clear-cell basal cell carcinoma: differentation from other clear cell tumors. Am J Dermatopathol 2007; 29: 208-209.

9. Starink TM, Blomjous CEM, Stoof TJ et al. Clear cell basal cell carcinoma. Histopathology 1990; 17: 401-405.

10. Kim DY, Cho SB, Chung KY, Kim YC. Clear cell basal cell carcinoma with sialomucin deposition. Yonsei Med J 2006; 47: 870-872.

11. Garg C, Agarwal A, Siddiqui B, Faridi S. Clear cell basal cell carcinoma - Un unusual entity in indian male. Ind J Med Report 2015; 4: 66-70.

12. Reck A, Pathmanathan T, Lagnado R, Parham DM. Clear cell basal carcinoma: an unusual variant. Histopathology 1996; 29: 390-391. 
www.odermatol.com

13. Oliver GF, Winkelmann RK. Clear-cell, basal cell carcinoma: histopathological, histochemical, and electron microscopic findings. J Cutan Pathol 1988; 15: 404-408.

14. Barr RJ, Alpern KS, Santa Cruz DJ, Fretzin DF. Clear cell basal cell carcinoma: an unusual degenerative variant. J Cutan Pathol 1993; 20: 308-316.
Copyright by Vladimír Bartoš, et al. This is an open access article distributed under the terms of the Creative Commons Attribution License, which permits unrestricted use, distribution, and reproduction in any medium, provided the original author and source are credited.

Source of Support: Nil, Conflict of Interest: None declared. 